\title{
The effect of inactivity on dietary intake and energy homeostasis
}

\author{
P. Ritz ${ }^{1 *}$ and M. Elia ${ }^{2}$ \\ ${ }^{1}$ Human Nutrition Research Centre-Auvergne, BP 321, Clermont-Ferrand 63009, France \\ ${ }^{2}$ Dunn Clinical Nutrition Centre, Hills Road, Cambridge CB2 2DH, UK
}

\begin{abstract}
Reduced physical activity commonly occurs in patients with disease or chronic disabilities, in the elderly, and in certain patients with obesity. Surprisingly, information on the effect of inactivity on energy homeostasis is scarce and often difficult to interpret. In models of reduced physical activity, such as space flights, bed-rest and confinement, subjects frequently lose weight $(<5 \%)$, predominantly in the form of fat-free mass. In some cases this is compensated by an increase in fat mass, which means that changes in weight are poor indicators of energy balance. The extent to which spontaneous reduction in energy intake (in most studies energy intake is fixed) compensates or overcompensates for the reduction in energy expenditure (mainly physical activity and to a small extent in BMR, typically $<6 \%$ ) is largely underexamined. Preliminary observations suggesting that there is a preferential selection of low-energy-dense foods (low in fat) require confirmation under carefully controlled experimental conditions. It is concluded that a comprehensive and systematic evaluation is needed to address the effects and relevance of various degrees of physical inactivity to energy homeostasis, in relation to disease and space medicine.
\end{abstract}

Physical inactivity: Energy balance: Body composition

\section{Inactivity and disease}

The commonest cause of severe inactivity is disease, which may be acute or chronic. Examples of acute diseases that cause inactivity are elective surgical and accidental injury, sepsis, myocardial infarction, prolapsed intervertebral disc, and any condition requiring intensive care. Such conditions may restrict patients to bed for a few days or a few weeks. In some situations inactivity may be total as in patients rendered unconscious by head injury or by sedatives. In other situations patients remain mobile but they are less active than usual, as in minor to moderately-severe illness.

Chronic diseases also produce varying degrees of inactivity, with some patients becoming housebound or bedbound for years. For example, several neurological conditions affecting motor function can restrict the patients to bed or a wheelchair, e.g. cerebrovascular accident, multiple sclerosis, motorneurone disease, Parkinson's disease and paraplegia. The British Artificial Nutrition Survey (Elia, 1998) suggests that most adult patients receiving home enteral tube feeding, mainly because of swallowing difficulties (e.g. cerebrovascular accident and multiple sclerosis), are very inactive; $52 \%$ are housebound and more than half these are bedbound. Prolonged inactivity may also be caused by arthritis (which may be of the inflammatory, e.g. rheumatoid arthritis, or non-inflammatory type, e.g. osteoarthritis), human immunodeficiency virus and malignancy (Elia \& Jebb, 1992; Elia, 1995; Macallan et al. 1995; Gibney et al. 1996; Paton et al. 1996; Kramer et al. 1998). Patients with malignancy also show reduced physical activity, partly because the inflammatory component of their disease causes lethargy, and partly because of pain, drug therapy and shortness of breath (e.g. in patients with lung cancer).

The specific effects of inactivity on metabolism and physiological functions, including appetite and energy homeostasis, are difficult to separate from those arising from the disease, its complications, and its treatment. Confounding variables include psychological disturbances (e.g. anxiety, depression and fear), nutritional status, pain, effects of drugs or infusion of fluids and electrolytes, and inflammation (which may be associated with a marked, e.g. fractures, sepsis, or little or no acute-phase response, e.g. prolapsed intervertebral disc.

\section{Anorexia and energy homeostasis in disease}

One of the most common consequences of disease is anorexia. It occurs acutely following elective surgical and 
accidental injury, thermal injury, sepsis, electrical injury and obstetric trauma, and a variety of inflammatory conditions (e.g. pancreatitis). In general, the more severe the acute diseases, the more severe the anorexia and the longer its duration. Retention of salt and water are also general features of the injury response, which are partly mediated by increased secretion of mineralocorticoids and antidiuretic hormone (Cuthbertson, 1980a,b). The combination of inactivity, anorexia and the tendency to retain fluid after injury may have teleological benefit. An injured, inactive and anorectic animal may increase its chances of survival by conserving energy and making itself less visible to predators than animals in poor physical condition that are driven to search for food and water by hunger and thirst.

Two examples are given here to illustrate the extent to which food intake is reduced after injury. Table 1 illustrates that food intake may be reduced by more than half in the first $3 \mathrm{~d}$ following elective abdominal surgery. Abdominal surgery may restrict food intake not only by producing anorexia, but also by causing post-operative ileus, peritonism, or occasionally intestinal obstruction. The anorectic effect of 'injury' also occurs after non-abdominal injury in the form of elective total hip replacement or accidental hip fracture (Table 2). However, it is possible to increase nutrient intake in these patients either by providing supplements (Stableforth, 1986; Keele et al. 1997) or by encouraging them to eat normal food. Indeed, on the request of research workers it is possible for patients undergoing total hip replacement to eat normal amounts of food (Elia, 1981) even when their appetite is suppressed (an observation which is also relevant to studies of immobilization uncomplicated by disease, see p. 117). Anorexia is also a feature of many chronic diseases including Crohn's disease, rheumatoid arthritis, human immunodeficiency virus, malignancy, parasitic conditions and chronic liver and lung disease (Jebb, 1997).

In general, total energy expenditure (TEE) is not increased by acute and chronic disease, despite the frequent elevation in BMR. This is because of the overriding effects of reduced physical inactivity (Elia \& Jebb, 1992; Elia, 1995; Macallan et al. 1995; Gibney et al. 1996; Paton et al. 1996; Kramer et al. 1998). Thus, the major cause of a negative energy balance in most acute and chronic diseases is a reduction in energy intake (EI). The extent to which inactivity contributes to this reduction in EI is unknown.

\section{Causes of reduced dietary intake in disease}

A detailed discussion of the mechanisms responsible for reduced dietary intake in disease is beyond the scope of the present paper (Plata-Salaman, 1996). However, the causes can be discussed at the different levels: mediators involved in appetite control, including hormones, cytokines and substrates; gastrointestinal factors, including painful

Table 1. Effect of elective abdominal surgery on energy and protein intake (Mean values and standard deviations)

\begin{tabular}{|c|c|c|c|c|c|c|}
\hline \multirow[b]{2}{*}{ Period of study (d) } & \multirow[b]{2}{*}{ No. of subjects } & \multicolumn{2}{|c|}{ Energy intake $(\mathrm{kJ} / \mathrm{d})$} & \multicolumn{2}{|c|}{ Protein intake ( $g / d)$} & \multirow[b]{2}{*}{ Reference } \\
\hline & & Mean & SD & Mean & SD & \\
\hline $1-3$ & 20 & 3603 & 233 & 40.5 & 3.0 & Rana et al. (1992) \\
\hline $1-7$ & 9 & 4620 & 233 & 52.9 & 23.0 & \\
\hline 1 & 43 & 2002 & 450 & 13.4 & 3.9 & Keele et al. (1997) \\
\hline 2 & 42 & 4103 & 484 & 31.1 & 4.3 & \\
\hline 3 & 40 & 5163 & 596 & 41.9 & 4.9 & \\
\hline 4 & 31 & 5667 & 621 & $46 \cdot 3$ & 5.5 & \\
\hline 5 & 25 & 5921 & 851 & 48.9 & $7 \cdot 3$ & \\
\hline 6 & 17 & 5842 & 1113 & $47 \cdot 7$ & 8.6 & \\
\hline 7 & 11 & 5942 & 1372 & 45.5 & 10.2 & \\
\hline $1>11$ & 12 & 3520 & & & & Hackett et al. (1979) \\
\hline 1 & 10 & 2077 & 655 & 4.9 & 7 & Kinney et al. (1968) \\
\hline 2 & 10 & 3340 & 1272 & 23.5 & 17 & \\
\hline 3 & 10 & 5713 & 2218 & 53.5 & 31 & \\
\hline
\end{tabular}

Table 2. Effect of elective total hip replacement and accidental fracture of neck of femur on energy and protein intake (Mean values and standard deviations)

\begin{tabular}{|c|c|c|c|c|c|c|c|}
\hline \multirow[b]{2}{*}{ Condition } & \multirow[b]{2}{*}{ Period after 'injury' (d) } & \multirow[b]{2}{*}{ No. of subjects } & \multicolumn{2}{|c|}{ Energy intake $(\mathrm{kJ} / \mathrm{d})$} & \multicolumn{2}{|c|}{ Protein intake $(g / d)$} & \multirow[b]{2}{*}{ Reference } \\
\hline & & & Mean & SD & Mean & SD & \\
\hline \multirow{7}{*}{ Total hip replacement } & -1 & 6 & 7560 & 3778 & & & Stratton et al. (1997) \\
\hline & 0 & 6 & 607 & 809 & & & \\
\hline & 1 & 6 & 3111 & 2681 & & & \\
\hline & 2 & 6 & 4216 & 2364 & & & \\
\hline & 3 & 6 & 4983 & 2802 & & & \\
\hline & 4 & 6 & 6063 & 2444 & & & \\
\hline & 5 & 6 & 6605 & 2752 & & & \\
\hline Fermoral neck fracture & $1-8$ & 61 & 3457 & 876 & 25 & 11 & Stableforth (1986) \\
\hline
\end{tabular}


mouth conditions that inhibit swallowing, and delayed gastric emptying which can occur even with non-abdominal or systemic injury (Jennings et al. 1995); whole-body changes, such as psychological disturbance, drugs, pyrexia and physical inactivity. Insights into the contribution of inactivity to the anorexia of disease are best understood through studies of inactivity uncomplicated by disease.

\section{Inactivity uncomplicated by disease}

Most human models of inactivity have been used to study the physiological consequences of space flights. Indeed, before the advent of the space programme, which used bedrest as a model for weightlessness, there was relatively little scientific interest in bed-rest and immobilization. A symposium on the abuse of rest as a therapeutic measure for patients with cardiovascular disease was held in 1944, and about a dozen scientific studies were reported in which the responses to prolonged starvation were investigated while the subjects rested in the horizontal position (summarized in NASA publications by Greenleaf et al. 1976, 1982). It is estimated that a total of about 1000 papers on bed-rest and fluid immersion have now been published, many before 1982 by Eastern Europeans who were stimulated into research by the Russian space programme (Greenleaf et al. 1976, 1982; Kollias et al. 1976). Despite these publications, it is surprising how little work has been undertaken on appetite. It is also surprising that review papers, book chapters or even books (for example, see Sandler \& Vernikos, 1986) on the physiological effects of inactivity make no reference to appetite. However, brief anecdotal information exists in some publications. Asher (1947), in his seminal paper The Dangers of Going to Bed, stated that appetite decreases after a few days of bed-rest. In a comprehensive review on the effects of bed-rest, Greenleaf (1984) stated that there is loss of appetite during bed-rest, but provided no information about the extent to which it is suppressed, or how soon it develops after the onset of bed-rest.

It is also not clear from this literature whether the decrease in food intake maintains or alters energy balance. Accurate longitudinal measurements of body composition can assess the effects of inactivity on energy balance, but few such studies have been undertaken. Furthermore, since dietary intake was fixed at different levels in various studies, and since a variable amount of exercise was allowed in these studies, it is not surprising that fat balance has been reported to vary from negative to positive (Greenleaf et al. 1976; Greenleaf, 1982).

Amongst the physiological changes observed during space flights are (1) a loss of fat-free mass (FFM), mainly in the form of bone mass and muscle tissues, (2) a fluid shift towards the splanchnic area, (3) a cardiovascular 'adaptation'. The changes seem to be the consequence of muscular deconditioning in the lower limbs, the body having no need to oppose gravitational forces. Information obtained during space flights has been complemented by data obtained during pre-flight ground-based experiments.

Two models mimicking muscular deconditioning have been generally used: prolonged bed-rest with or without head-down tilt (HDT; generally $-6^{\circ}$, which is achieved by lifting the foot of the bed up by about $200 \mathrm{~mm}$ ); confine- ment in a limited space. In both these situations there is a certain degree of stress, but this is probably greater during space missions, partly because of potentially life-threatening complications, and partly because of a heavy mental workload imposed on the crew. However, substantial stress may also occur during confinement and isolation, affecting EI and energy balance, as discussed later (see p. 120). It is noteworthy that no study has obtained comprehensive physiological information about energy balance during normal bed-rest. The available information, (e.g. on loss of muscle mass and function), is therefore, mostly a by-product of studies with other primary aims. Information on $\mathrm{EI}$ is even more scarce. Although great attention is paid to the psychological consequences of inactivity, appetite has received very little attention. The patchy information available on energy homeostasis during space flights, bed-rest and confinement will be summarized.

\section{Space flights}

Although a limited number of human subjects have undertaken space flights, there is a considerable interest in the physiological and behavioural consequences of such missions. Mainly for operational reasons, the specific physiology of man in space is a key issue in Western countries. Indeed, amongst other reasons it is critical not to take on board more food than necessary, since the craft would then be heavier and would require more fuel. It is also critical that astronauts are absolutely fit to manoeuvre the spacecraft when re-entering the atmosphere.

\section{Body composition changes}

During space flights human subjects often lose weight. The average weight losses during thirty-three Apollo (6$12 \mathrm{~d})$ missions and nine Skylab (28-84 d) missions were 3.5 and $3.0 \mathrm{~kg}$ respectively (Krebs et al. 1990). Changes in body composition have been observed in crew members. After an initial fluid loss (Leonard et al. 1983; Lane \& Schulz, 1992), there is a decline in muscle mass and bone mass, all of which contribute to loss of FFM (Leonard et al. 1983; Herbison \& Talbot, 1985; Lane, 1992). This decline in FFM is not always accompanied by a loss of fat. Indeed, during prolonged space missions and during missions in which food intake is increased, fat mass tends to replace the lost FFM (Lane, 1992). However, there is a lack of information on measurements of both EI and energy expenditure, and assessment of appetite sensations. Digestibility and energy absorption appear to be unaffected by microgravity (Krebs et al. 1990).

\section{Changes in energy expenditure}

It appears that TEE during a space flight is of similar magnitude to that before the flight (Lane, 1992; Lane et al. 1997). A decline in TEE would be expected as a result of a reduction in FFM, lower limb unloading, and reduced energy cost of weight-bearing activities (Rambaut et al. 1977). Furthermore, since cabins are very small, the crews of between two and five will experience a reduction 
in their movements. However, in a review of the changes in the components of energy expenditure, Greenleaf (1989) indicated that BMR, which would be expected to be increased by stress has not been measured during space flights. In addition, exercise programmes have been increasingly included during prolonged space missions as countermeasures to muscular deconditioning. Furthermore, the demands of duties associated with the mission may also serve to elevate the energy expenditure of crew members to counter the decreased energy requirements of weightbearing activities (Greenleaf, 1989). Thus, TEE:BMR (which is a classical index of the physical activity level) might not be a good indicator during space flights until all the components of TEE are measured.

\section{Food and macronutrient intake}

Food consumption during American and Russian flights was lower than TEE (Lane, 1992). Since more food was generally available than actually consumed, a 'spontaneous' reduction in EI was responsible for the negative energy balance. Other short-term (3-9d, Stein \& Gaprindashvili, 1994) and medium-term flights (up to $59 \mathrm{~d}$, Rambaut $e t$ al. 1977) have also reported reduced food intake compared with pre-flight measurements, but EI during longer flights has been reported to be increased, especially in relation to cellular mass (Rambaut et al. 1977). However, methodological considerations limit the reliability of this information. Only rarely have EI and energy expenditure been measured for individual subjects. Combined measurements have usually been made for the entire crew (two to five members in shuttle missions; Lane, 1992). Furthermore, values for EI, which were estimated from the disappearance of food from the food-stocks, are more reliable than those for TEE, which were estimated from changes in $\mathrm{CO}_{2}$ appearance in the cabin. An alternative approach was taken by Lane et al. (1997) who measured EI and TEE (doubly-labelled-water method) in individual subjects both before and during space flights. They reported that EI during $8-14 \mathrm{~d}$ flights was about $23 \%$ lower than the pre-flight measurements. The subjects lost weight and were in negative energy balance, since their EI was about $25 \%$ lower than TEE (Table 3).

The reasons for the reduced EI during short- and medium-term space flights include: (1) space motion sickness (a common but not ubiquitous symptom affecting $50-70 \%$ of astronauts in the early phase of the flight), (2) preoccupation with mission objectives, (3) stress, (4) a reported sensation of gastrointestinal fullness (which may be the result of altered gastrointestinal function), (5) possible acute-phase response mediated by cytokines (Stein \& Schluter, 1994). Thus, appetite control may be altered during space flight, and Lane \& Schulz (1992) concluded that this undoubtedly plays a role. This last possibility is supported by the finding that during the Skylab missions there was a tendency for astronauts to increase carbohydrate intake from 5.8 to $6.6 \mathrm{MJ} / \mathrm{d}$ and for fat intake to decrease from 4.0 to $3.1 \mathrm{MJ} / \mathrm{d}$ (Lane, 1992). Similar findings were observed during American shuttle flights; when compared with pre-flight values, carbohydrate intake increased from 54 (SD 8) to 59 (SD 5) \% EI, while fat intake decreased from 31 (SD 6) to 27 (SD 4) \% EI (Lane et al. 1997). It is noticeable that during both Skylab and shuttle missions protein intake did not change (Lane, 1992; Lane et al. 1997).

These observations together with those of markedly negative. energy and nutrient balances, which were influenced by mission duration, suggest that the regulation of nutrient and energy balances is altered during space flight. The extent to which these changes are due to underlying metabolic processes (e.g. substrate cycling and tissue catabolism) on the one hand, and changes in appetite and macronutrient selection on the other hand is uncertain.

However, during space flight other factors need to be considered. For operational reasons, during the first flights food was only available in 'tubes' in the form of cold prepacked mouthfuls of elemental diets, which were monotonous and unappetizing. It is only during the most recent missions that hot water has been made available, permitting some degree of cooking and greater food choice (Lane, 1992).

Another confounding variable was the implementation of exercise regimens to counterbalance the loss of muscle mass. However, the extent and type of exercise in space flights have often been poorly documented, making it difficult to relate changes in TEE to changes in EI.

\section{Bed-rest studies}

Since only a small number of individuals have engaged in space flight, other terrestrial models of weightlessness and inactivity have been used to investigate physiological changes. Prolonged bed-rest is an appropriate model to mimic microgravity-induced changes in energy metabolism (Greenleaf, 1989; Lane, 1992). HDT bed-rest is generally viewed as a preferable model because it elicits some of the early physiological effects of microgravity with greater fidelity.

Table 3. Energy balance ( $\mathrm{MJ} / \mathrm{d})$ during space missions

\begin{tabular}{|c|c|c|c|c|c|c|}
\hline \multirow[b]{2}{*}{ Mission } & \multicolumn{2}{|c|}{ Pre-flight } & \multicolumn{2}{|c|}{ Flight } & \multirow[b]{2}{*}{ Wt loss $(\mathrm{kg})$} & \multirow[b]{2}{*}{ Reference } \\
\hline & El & TEE & El & TEE & & \\
\hline 28 d Skylab & 11.9 & & 12.2 & & -2.3 & Lane (1992) \\
\hline $59 \mathrm{~d}$ Skylab & 13.1 & & 12.3 & & -3.0 & Lane (1992) \\
\hline 81 d Skylab & $12 \cdot 3$ & & 12.3 & & -1.4 & Lane (1992) \\
\hline 8-14 d Shuttle & 11.4 & $12 \cdot 4$ & 8.8 & 11.7 & -1.5 & Lane et al. (1997) \\
\hline
\end{tabular}

$E l$, energy intake; TEE, total energy expenditure. 


\section{Body composition changes}

Loss of muscle mass has also been observed during bed-rest, both with (Greenleaf, 1989; Leblanc et al. 1992; Gretebeck et al. 1995; Ferrando et al. 1996) and without HDT (Krebs et al. 1990). Fluid loss, bone loss and electrolyte imbalances also occur during prolonged bed-rest. However, loss of fat mass is not always apparent. Indeed, both fat and energy balances may be positive. For example, in two studies ( 7 d bed-rest with HDT; Gretebeck et al. 1995 and 5 weeks bed-rest without HDT; Krebs et al. 1990) in which volunteers were asked to consume a diet to maintain body weight (EI approximately $10.9 \mathrm{MJ} / \mathrm{d}$ ), the decline in FFM was compensated by an increase in fat mass (associated with a positive energy balance).

\section{Energy expenditure}

Spontaneous physical activity is obviously reduced during bed-rest. TEE, therefore, is also reduced (by $22 \%$ compared with the pre-bed-rest period in the Gretebeck et al. (1995) experiment. Greenleaf (1989) has carefully reviewed the available information on the effect of bed-rest on resting metabolic rate (RMR). Most, but not all, studies reported a decrease in RMR. However, the results from some of the early studies are questionable, since RMR was measured for varying lengths of time under non-standardized conditions following a variable period of fasting. In the three studies in which RMR was measured under controlled conditions, RMR was either unchanged (Greenleaf, 1989) or increased in the short term ( $36 \mathrm{~h}$ bed-rest; Acheson et al. 1995), or decreased in the longer term (after $42 \mathrm{~d}$ HDT bed-rest; Ritz et al. 1998). A decrease can be explained fully by the decline in FFM (Ritz et al. 1998). Since diet-induced thermogenesis is not affected by bed-rest (Ritz et al. 1998), the decrease in TEE appears to be almost completely mediated by the reduction in physical activity. Other information relevant to bed-rest and energy homeostasis includes a decrease in maximum $\mathrm{O}_{2}$ uptake (White et al. 1966; Saltin et al. 1968), work capacity (Kakurin et al. 1970), and impaired thermoregulation (onset of sweating and feelings of coldness occur at a lower temperature; Williams \& Reese, 1972; Greenleaf et al. 1976). In addition, there is a decrease in mechanical energy efficiency following a period of bedrest (Kakurin et al. 1964), which can be explained by lessefficient muscular coordination on resumption of physical activity (Garfinkel et al. 1969).

\section{Energy and macronutrient intake}

Very limited information is available about spontaneous food and energy intake during bed-rest, despite the great opportunities made available from many bed-rest studies. Gretebeck et al. (1995) and Krebs et al. (1990) fed their volunteers on food of fixed amount and composition, thus making it impossible to detect any spontaneous changes. Demaria-Pesce et al. (1992) showed a reduction in spontaneous intake in three subjects during $28 \mathrm{~d}$ bed-rest in an HDT position. We have observed similar findings during $42 \mathrm{~d}$ bed-rest in the study mentioned previously (Ritz et al. 1998). While this latter study was not specifically designed to examine in detail appetite sensations and feeding behaviour, a number of interesting patterns emerged. The 1994 bed-rest campaign, organized by the European Space Agency and the French Centre National d'Etudes Spatiales, involved a study designed to measure RMR, diet-induced thermogenesis and fuel oxidation $15 \mathrm{~d}$ before and on day 8 and 42 of bed-rest in a HDT position in seven healthy subjects (Ritz et al. 1998). Volunteers were also studied for a further $12 \mathrm{~d}$ after the bed-rest period, when they had become ambulant. Although subjects were expected to lose weight, the same amount of food $(146 \mathrm{~kJ}$ per $\mathrm{kg}$ initial body weight) with the same composition $(50,35$ and $15 \%$ energy as carbohydrate, lipid and protein respectively) was deliberately provided throughout the experiment. Volunteers were allowed to eat ad libitum but they were not allowed to snack. Food items were weighed before the meals and any food left over was weighed immediately after the meals. Calculations of EI and macronutrient intakes were performed using a computer program (Profil $^{\circledR}$, release $2 \cdot 1$; ACIM, Saint-Doulchard, France) based on French food composition tables. Fig. 1 shows that body weight and EI were lower during the bed-rest period compared with prebed-rest. EI declined by $18 \%$ after 4 weeks of bed-rest and by $16 \%$ after 6 weeks. When subjects were allowed to stand, EI increased significantly. On the last day of the experiment EI was still lower by $1 \cdot 1 \mathrm{MJ} / \mathrm{d}$ compared with the pre-bed-rest period. There was a weak relationship between body weight changes and changes in EI (which explained $26 \%$ of the variance).

The intakes of fat, carbohydrate and protein (g/d) significantly decreased during bed-rest. However, the proportion of EI derived from fat decreased, that from carbohydrate increased, and that from protein did not change. During the post bed-rest period fat intake increased. Thus, the reduction in EI was due largely to a decrease in fat intake.

Since the study of Ritz et al. (1998) was not specifically designed to assess changes in EI and macronutrient intake, it would be important to replicate these findings in a study specifically designed to assess these variables. This approach would avoid possible artifacts arising from the protocol, such as the presentation of the food. However, a number of pertinent observations were made in the Ritz et al. (1998) study.

First, a reduction in fat intake and an increase in carbohydrate intake (expressed both in grams and relative to EI) has been noticed during Shuttle and Skylab missions. It is possible, therefore, that both weightlessness and HDT bed-rest may lead to alterations in macronutrient selection. In our bed-rest study the availability of food energy was kept constant, but more and more food was left over on the plates as the study progressed. The reduction in EI was, therefore, the direct consequence of a spontaneous reduction in food intake. Volunteers left an increasing proportion of fat, but maintained the proportion of energy as protein. All these changes were reversed as soon as the bed-rest period was over. Similar changes in macronutrient selection were noted during space flights of both short duration (Lane et al. 1997) and long duration (up to $84 \mathrm{~d}$; Lane, 1992). It is unlikely, therefore, that the decreased fat intake was the consequence of either methodological measurement biases or differences in palatability of food items. 


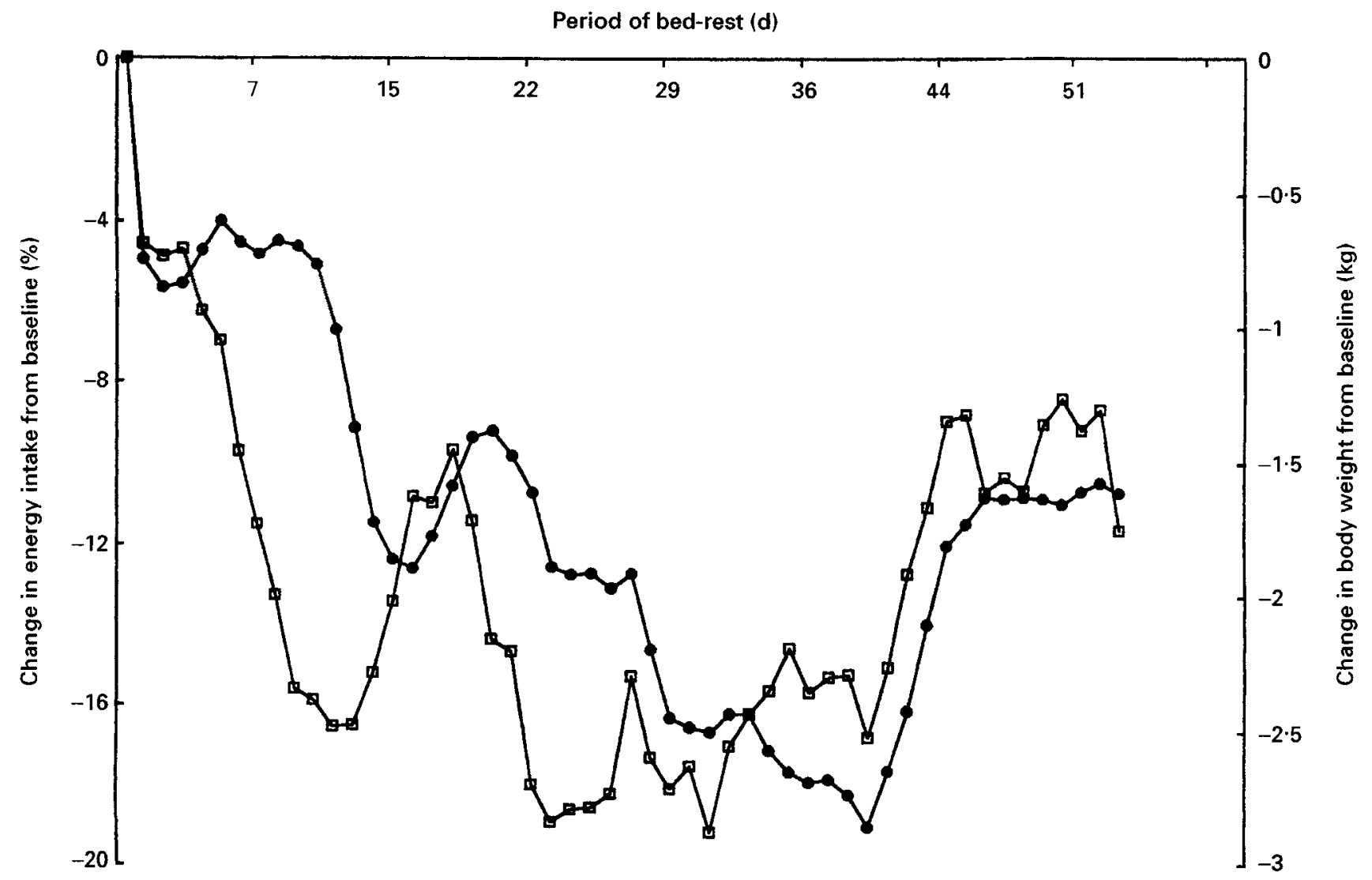

Fig. 1. Changes in energy intake $(\square)$ and body weight $(\bullet)$ during the head-down tilt $\left(-6^{\circ}\right.$, achieved by lifting the foot of the bed up by about $200 \mathrm{~mm}$ ) period (days 1-40) and the recovery period (days $41+$ ). Values are expressed as percentage of the mean value calculated over the second week of the baseline period (day 0 ).

It is difficult to assess whether the diminished EI observed under conditions of microgravity represents an appropriate response to decreased physical activity or to the effects of confounding variables such as motion sickness, stress and ingestion of monotonous unappetizing food.

\section{Confinement experiments}

Since both space flights and bed-rest involve a certain degree of confinement, the European Space Agency implemented the European Manned Space Infrastructure programme, with the aim of studying the psychological and physiological effects of prolonged isolation and confinement on crew performance in simulated space environments. In 1991, four volunteers were confined in a $92 \mathrm{~m}^{3}$ chamber for $60 \mathrm{~d}$, during which measurements of EI and energy expenditure were made (Maillet et al. 1998). A true reduction in physical activity was observed, since during the entire period of the study the crew members exercised on a cycloergometer for only 2-12h. All four subjects lost weight (1.8 (SD 0.9) $\mathrm{kg}$ ), but most of the weight loss occurred by day $27(-1.6$ (SD 0.8$) \mathrm{kg}$ ). TEE was measured, using the doubly-labelled-water method, before entering the chamber and between days 27 and 41 . TEE was reduced in the chamber by a mean of $3.6 \mathrm{MJ} / \mathrm{d}$ (from 14.9 to $11.3 \mathrm{MJ} / \mathrm{d}$, or $-24 \%$, range -6 to $-38 \%$ ). RMR and other components of energy expenditure were not measured. Since the experiment was a ground-based simulation study, the problem of providing an adequate food supply was greatly facilitated by the availability of a large storage capacity, which included freezers, refrigerators and microwave ovens. This made it possible for each crew member to select a variety of fresh, frozen, canned and dehydrated foods (Milon et al. 1996). Although the subjects were close to energy balance (EI 10.9 MJ/d, TEE $11.3 \mathrm{MJ} / \mathrm{d}$, balance -0.3 (SD 1.1, range -2.4 to +2.5 ) $\mathrm{MJ} / \mathrm{d}$ ), unfortunately no temporal changes in energy and macronutrient intake were reported.

\section{Conclusion}

All the models described in the present paper involve reductions in physical activity and TEE. In short-term space missions, major reductions in EI may lead to a negative energy balance, particularly when stress and space motion sickness are severe. In the few terrestrial models of inactivity in which food intake was measured EI decreased, but whether this is totally, partially, or overcompensated for by the reduction in physical activity is uncertain. Preliminary observations of food selection suggest a preference for the low-energy-dense foods (low in fat) but these observations require confirmation. The lack of information on the shortand long-term effects of inactivity is striking. This is 
surprising in view of the frequency of acute and chronic diseases (the number of UK hospital admissions alone are twelve million per year), and disabilities associated with increasing age, and increasing evidence of obesity. Space exploration stimulated research into inactivity and bed-rest, but many issues still need to be resolved, including the confounding effects of confinement, psychological stresses and individual variability in the responses. Thus, cultural, social and behavioural changes need to be studied in association with the physiological changes.

\section{References}

Acheson KJ, Décombaz J, Piquet-Welsch C, Montignon F, Decarli B, Bartholdi I \& Fern E (1995) Energy, protein and substrate metabolism in simulated microgravity. American Journal of Physiology 269, R252-R260.

Asher RAJ (1947) The dangers of going to bed. British Medical Journal 4, 967-968.

Cuthbertson DP (1980a) Alterations in metabolism following injury: Part I. Injury 11, 175-189.

Cuthbertson DP (1980b) Alterations in metabolism following injury: Part II. Injury 11, 286-303.

Demaria-Pesce VH, Verger P, Guell A \& Louis-Sylvestre J (1992) Changes in voluntary eating behaviour during a 28 day head down bed rest experiment: preliminary results. The Physiologist 35, S210-S211.

Elia M (1981) Metabolic aspects of injury, starvation, and other conditions in man. MD Thesis, University of Manchester.

Elia M (1995) Changing concepts of nutrient requirements in disease: implications for artificial nutritional support. Lancet 345, 1279-1284.

Elia M (1998) The 1997 Report of the British Artifical Nutrition Survey. London: British Association of Parenteral and Enteral Nutrition.

Elia M \& Jebb SA (1992) Changing concepts of energy requirements in critically ill patients. Current Medical Literature in Clinical Nutrition 1, 35-38.

Ferrando A, Lane H, Stuart C, Davis-Street J \& Wolfe R (1996) Prolonged bed rest decreases skeletal muscle and whole body protein synthesis. American Journal of Physiology 270, E627-E633.

Garfinkel VS, Pal'tser YI, Fel'dman AG \& El'ner AM (1969) Changes in certain human motor functions after prolonged hypodynamia. Problemy Kosmicheskoy Biologii 13, 148-169.

Gibney E, Elia M, Jebb SA, Murgatroyd P \& Jennings G (1996) Total energy expenditure in patients with small cell lung cancer: Results of a validated study using the bicarbonate-urea method. Metabolism 46, 1412-1417.

Greenleaf JE (1982) Physiological consequences of reduced physical activity during bed-rest. Exercise and Sport Sciences Review 10, 84-117.

Greenleaf JE (1984) Physiological responses to prolonged bed-rest and fluid immersion in humans. Journal of Applied Physiology 57, 619-633.

Greenleaf JE (1989) Energy and thermal regulation during bed rest and spaceflight. Journal of Applied Physiology 67, 507516 .

Greenleaf JE, Greenleaf CJ, Van Derveer D \& Dorchak J (1976) Adaptation to Prolonged Bed-rest in Man: a Compendium of Research. NASA Technical Memo X3307, pp. 1-180. Washington, DC: NASA.

Greenleaf JE, Silverstein J, Bliss J, Langeheim V, Rossow H \& Chao C (1982) Physiological Responses to Prolonged Bed-rest and Fluid Immersion in Man: A Compendium of Research
(1974-1980). NASA Technical Memo 81324, pp. 1-110. Washington, DC: NASA.

Gretebeck RJ, Schoeller DA, Gibson EK \& Lane HW (1995) Energy expenditure during antiorthostatic bed-rest (simulated microgravity). Journal of Applied Physiology 78, 2207-2211.

Hackett AF, Yeung CK \& Hull GL (1979) Eating patterns in patients recovering from major surgery - a study of voluntary food intake and energy balance. British Journal of Surgery 66, 415-418.

Herbison GJ \& Talbot JM (1985) Muscle atrophy during space flight: research needs and opportunities. The Physiologist 28 , 520-527.

Jebb SA (1997) Anorexia: a neglected clinical problem. In Physiology, Stress and Malnutrition: Functional Correlates and Nutritional Intervention, pp. 151-181 [JM Kinney and HN Tucker, editors]. Philadelphia and New York: Lippincott-Raven.

Jennings G, Lunn PG \& Elia M (1995) The effect of endotoxin on gastrointestinal transit time and intestinal permeability. Clinical Nutrition 14, 35-41.

Kakurin LI, Kamkoviskiy BS, Georiyeveskiy VS, Purakhan YN, Cherenikhin MA, Mikhaylor BN, Pemukhov BN \& Buryikor YN (1970) Functional disturbances during hypokinesia in man. Voprosy Kurotologii Fiz'ioterapii $i$ Lechebonoy Fizicheskoy Kul'tury 35, 19-24.

Kakurin LI, Katkoviskiy BS, Kozlov AN \& Mukharlyamor NM (1964) Effect of hypokinesia on certain indices of efficiency and respiratory function in man. Aviation and Space Medicine 35, $192-194$.

Keele AM, Bray MJ, Emery PW, Duncan HD \& Silk BDA (1997) Two phase randomised controlled clinical trial of post-operative and dietary supplements in surgical patients. Gut 40, 393-397.

Kinney JM, Lang CL, Gump FE \& Duke JH (1968) Tissue composition of weight loss in surgical patients. I Elective operation. Annals of Surgery 168, 459-474.

Kollias J, Van Derveer D, Dorchak KJ \& Greenleaf JE (1976) Physiologic Responses to Water Immersion in Man. A Compendium of Research. NASA Technical Memo X3308, pp. 1-87. Washington, DC: NASA.

Kramer JA, Dewit O \& Elia M (1998) Relationship between physical activity level, performance status, and quality of life in patients with inoperable lung cancer. Proceedings of the Nutrition Society 57, 106A.

Krebs J, Schneider V, Evans H, Kuo M \& Leblanc A (1990) Energy absorption, lean body mass and total body fat changes during five weeks of continuous bed rest. Aviation Space and Environmental Medicine 61, 314-318.

Lane H (1992) Energy requirements for space flights. Journal of Nutrition 122, 13-18.

Lane H \& Schulz L (1992) Nutritional questions relevant to space flight. Annual Review of Nutrition 12, 257-278.

Lane HW, Gretebeck RJ, Schoeller DA, Davis-Street J, Socki RA \& Gibson EK (1997) Comparison of ground-based and space flight energy expenditure and water turnover in middleaged healthy male US astronauts. American Journal of Clinical Nutrition 65, 4-12.

Leblanc A, Schneider V, Evans H, Pientok C \& Spector E (1992) Regional changes in muscle mass following 17 weeks of bed rest. Journal of Applied Physiology 73, 2172-2178.

Leonard JI, Leach C \& Rambaut PC (1983) Quantitation of tissue loss during prolonged space flight. American Journal of Clinical Nutrition 38, 667-679.

Macallan DC, Noble C, Baldwin C, Jebb SA, Prentice AM, Coward WA, Sawyer MB, McManus TJ \& Griffin GE (1995) Energy expenditure and wasting in human immunodeficiency virus infection. New England Journal of Medicine 333, 83-88.

Maillet A, Gunga HC, Normand S, Allevard AM, Cotter-Emard JM, Pachiaudi C, Kirsch K, Gauquelin G \& Gharib C (1998) 
Effects of a 60-day confinement on the blood pressure, hormonal responses and body fluids of a mixed crew. Journal of Gravitational Physiology (In the Press).

Milon H, Decarli B, Adine AM \& Kihm E (1996) Food intake and nutritional status during EXEMSI. In Advances in Space Biology and Medicine, pp. 79-91 [SJ Bonting, editor]. London: JAI Press Inc.

Paton NIJ, Elia M, Jebb SA, Jennings G, Macallan DC \& Griffin GE (1996) Total energy expenditure and physical activity measured with the bicarbonate-urea method in patients with human immunodeficiency virus infection. Clinical Science 91, 241-245.

Plata-Salaman CR (1996) Anorexia during acute and chronic disease. Nutrition 12, 69-78.

Rambaut PC, Leach CS \& Leonard JI (1977) Observations in energy balance in man during spaceflight. American Journal of Physiology 233, R208-R212.

Rana SK, Bray J, Menzies-Gow N, Jameson J, Payne James JJ, Frost P \& Silk DBA (1992) Short term benefits of post-operative oral dietary supplements in surgical patients. Clinical Nutrition 11, 337-344.

Ritz P, Acheson KJ, Gachon P, Vico L, Alexandre C, Bernard J \& Beaufrère B (1998) Energy and substrate metabolism during 42 days bed-rest in a head down tilt position. European Journal of Applied Physiology (In the Press).
Saltin B, Blomqvist G, Mitchell JH, Johnson RL, Wildenthal K \& Chapman CB (1968) Response to exercise after bed-rest and after training. A longitudinal study of adaptive changes in oxygen transport and body composition. Circulation 38, Suppl. 7, VII-1-VII-78.

Sandler H \& Vernikos J (editors) (1986) In Inactivity: Physiological Effects. London: Academic Press.

Stableforth PG (1986) Supplement feeds and nitrogen and calorie balance following femoral neck fracture. British Joumal of Surgery 73, 651-655.

Stein TP \& Gaprindashvili T (1994) Spaceflight and protein metabolism, with special reference to humans. American Journal of Clinical Nutrition 60, 806S-819S.

Stein TP \& Schluter MD (1994) Excretion of IL-6 by astronauts during spaceflight. American Journal of Physiology 266, E448E452.

Stratton RJ, Dewit O, Crowe E, Jennings G, Villar RN \& Elia M (1997) Plasma leptin, energy intake and hunger following total hip replacement surgery. Clinical Science 93, 113-117.

White PD, Nyberg JW, Finney LM \& White WJ (1966) A Comparative Study of the Physiological Effects of Immersion and Bedrest. Report DAC-59226. Santa Monica, CA: Douglas Aircraft Co Inc.

Williams BA \& Reese RD (1972) Effect of Bed-rest on Thermoregulation. Aerospace Medical Association Preprint, pp. 140141. Washington, DC: Aerospace Medical Association. 